\title{
Diameter Expanded Conductor Self-Damping Characteristics
}

\author{
Y. Qi \\ China Electric Power Research Institute \\ Beijing, China \\ North China Electric Power University \\ Beijing, China \\ J.C. Wan \\ China Electric Power Research Institute \\ Beijing, China
}

\author{
K.J. Zhu \\ China Electric Power Research Institute \\ Beijing, China \\ B. Liu \\ China Electric Power Research Institute \\ Beijing, China
}

\begin{abstract}
Self-damping test and analysis for one type of diameter expanded conductor JLK/G1A-530(630)/45-33.75 are performed, and analytical expression and frequency response characteristics are obtained. Comparison and analysis between normal conductor JL/G1A-630/45-45/7 and diameter expanded conductor JLK/G1A-530(630)/45-33.75 are given. And the main protection Aeolian vibration frequency range of the diameter expanded conductor is determined as from 0 to $30 \mathrm{~Hz}$.
\end{abstract}

\section{Keywords-diameter expanded conductor; self-damping}

\section{INTRODUCTION}

Aeolian vibration occurs commonly on overhead conductors under wind condition. Long term Aeolian vibration can easily cause the conductor strands broken and electric fittings damage. In order to restrain Aeolian vibration, anti-vibration devices are usually installed on the overhead conductors. Part of the wind energy input to the conductors is absorbed by the anti-vibration devices, and part is absorbed by the conductor itself. As a result, the nature of the conductor itself to absorb vibration energy, which is called self-damping characteristic, is an important part of the conductor anti-vibration system design. For diameter expanded conductor is first applied to UHV power transmission line project, master the self-damping characteristics of the conductor is of great significance for a comprehensive grasp of the conductor performance, conductor anti-vibration design, and operation and maintenance of the transmission line[1][2].

\section{CONDUCTOR SELF-DAMPING}

Conductor self-damping reflects the capability of absorbing vibration energy under different vibration states (different frequency, different antinode amplitude). It is the intrinsic characteristic of structure or material, mainly composed of three aspects:

1) Conductor strands hysteresis damping, energy dissipation in each strand.

2) When slip occurs between conductor strands, energy dissipation caused by the friction effect between the contact surfaces of the strands.
3) Energy dissipation caused by viscous friction between conductor and air.

Among them, the second is the main part of the self-damping effect. Conductor self-damping is influenced by many factors such as conductor material, structure and tension, etc. Self-damping can be described as formula (1).

$$
P_{c}=\pi / 2 H f(Y / Z)^{m} \lambda^{-n}
$$

Where, $\mathrm{m} 、 \mathrm{n} 、 \mathrm{H}$-constant, determined by test

Y- conductor antinode double amplitude

$\lambda$ - conductor vibration wavelength

$\mathrm{m}, \mathrm{n}, \mathrm{H}$ should be determined by test, because they are very complicated, and there is no theoretical calculation method for solving them.

\section{CONDUCTOR SELF-DAMPING TEST TECHNOLOGY}

\section{A Test System}

Conductor self-damping test system is mainly composed of conductor tension and fixation devices, conductor vibration exciting device, data acquisition system, data processing analysis system and other parts. Conductor self-damping test span is shown in figure 1 .

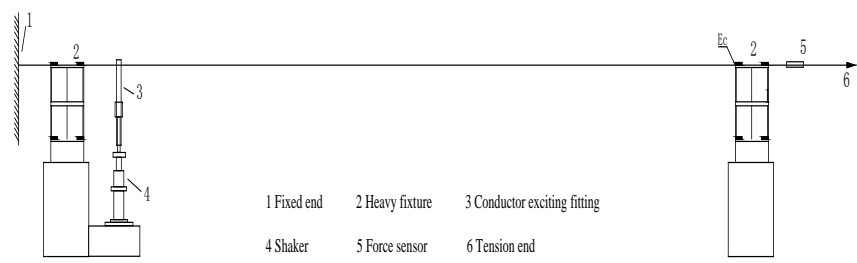

FIGURE I. ARRANGEMENT OF CONDUCTOR SELF-DAMPING TEST SPAN 


\section{B $\quad$ Test Method}

Power method is used in the conductor self-damping test. First, tension the conductor on the test span according to the requirement, then exciting the conductor by a shaker on one end of the test span to simulate Aeolian vibration of different frequencies. During the test, the vibration force, vibration velocity, antinode amplitude and dynamic bending strain at the exit of suspension clamp should be recorded. Finally, through data processing, conductor self-damping analytical expression is given[3].

\section{DIAMETER EXPANDED CONDUCTOR SELF-DAMPING TEST RESULTS}

\section{A Test Sample Parameters}

Self-damping test is performed for two samples of diameter expanded conductor JLK/G1A-530(630)/45-33.75 from two different manufactures, and the parameters of the conductor are listed in table 1.

TABLEI. TEST SAMPLE PARAMETERS

\begin{tabular}{cccc}
\hline Type & $\begin{array}{c}\text { Diameter } \\
\mathbf{( m m})\end{array}$ & $\begin{array}{c}\text { Unit } \\
\text { mass } \\
\mathbf{( k g / k m )}\end{array}$ & $\begin{array}{c}\text { Rated tensile } \\
\text { strength(kN) }\end{array}$ \\
\hline JLK/G1A-530(630)/45-33.75 & 33.75 & 1806.5 & 134.26 \\
\hline
\end{tabular}

B Diameter Expanded Conductor Self-Damping Expression

The JLK/G1A-530(630)/45-33.75 conductor self-damping expression can be obtained by fitting the test data, and the analytical expression of conductor self-damping is shown as formula 2[4].

$$
\Pi \chi=\sqrt{ }(\phi, \Psi)=10 \circledast(\Psi / \Delta)<
$$

$\mathrm{f}$

Where, coefficient $\alpha, \beta$ are expressions related to frequency

f- test frequency $(\mathrm{Hz})$

D- conductor diameter (mm)

Y- conductor antinode double amplitude

$\alpha, \beta$ of the two test samples are shown in table 2 .

TABleil. COEFficient A, B of Two Test SAmples

\begin{tabular}{ccc}
\hline No. & Expression of $\boldsymbol{\alpha}$ & Expression of $\boldsymbol{\beta}$ \\
\hline 1 & $2.199017+0.004481 f$ & $-0.020903+0.137161 f$ \\
& & $-0.000847 f^{2}$ \\
\hline 2 & $2.737031-0.000432 f$ & $-0.007067+$ \\
& & $0.150647 f-0.001048 f^{2}$ \\
\hline
\end{tabular}

C Contrast analysis of Diameter Expanded Conductor Self-Damping Characteristics

In order to make a clear contrast analysis, self-damping test for two JLK/G1A-530(630)/45-33.75 conductor samples and one JL/G1A-630/45-45/7 conductor sample has been performed, and self-damping frequency response characteristic curves of these three samples are drawn in the same coordinate system as figure 2 .

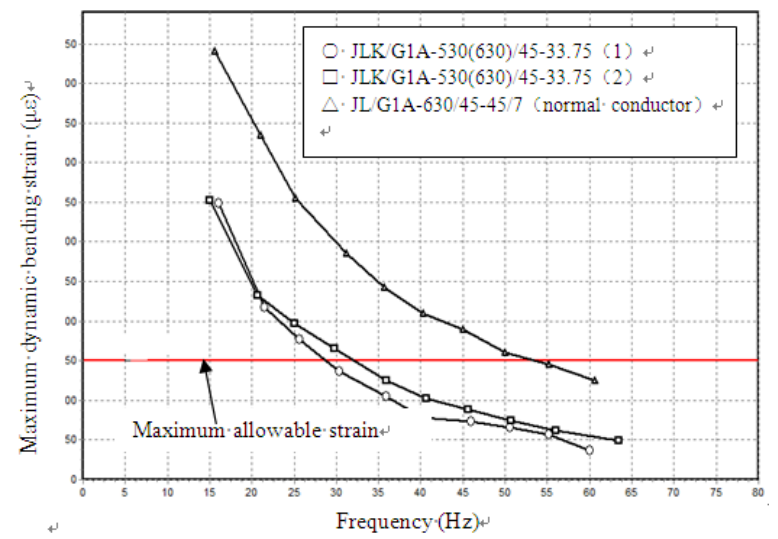

FIGURE II. SELF-DAMPING FREQUENCY RESPONSE CHARACTERISTIC CURVES OF DIAMETER EXPANDED CONDUCTORS AND NORMAL CONDUCTOR

According to the dynamic bending strain at the exit of suspension clamp, for two diameter expanded conductor samples, self-damping performance of them is very close. And for diameter expanded conductor samples and normal conductor sample, self-damping performance of JLK/G1A-530(630)/45-33.75 is superior to that of JL/G1A-630/45-45/7. Because with the same conductor diameter and strand diameter, the strands of diameter expanded conductor are not as tight as that of normal conductor, which leads to a more sufficient friction among the strands during the conductor vibration. According to the maximum allowable strain requirement, the two diameter expanded conductor samples' bending strain exceeds the range of allowable strain only in low frequency (below $30 \mathrm{~Hz}$ ) vibration. So, for anti-vibration design of diameter expanded conductor JLK/G1A-530(630)/45-33.75, the main protection frequency range is below $30 \mathrm{~Hz}$.

\section{$\mathrm{V}$ CONCLUSIONS}

1) Self-damping performance of diameter expanded conductor JLK/G1A-530(630)/45-33.75 is superior to that of normal conductor JL/G1A-630/45-45/7.

2) The main protection frequency range of Aeolian vibration of diameter expanded conductor JLK/G1A-530(630)/45-33.75 is from 0 to $30 \mathrm{~Hz}$.

\section{REFERENCES}

[1] Zheng Yuqi. Overhead transmission line Aeolian vibration [M].Beijing: Water Conservancy and Electric Power Press, 1987: 2-56 (in Chinese)

[2] Zhang Dian-sheng. Design manual of high voltage power transmission line in power engineering $[\mathrm{R}]$. China Power Press, 2007:179-23 (in Chinese)

[3] Xu Naiguan, Wang Jingchao. Conductor self-damping test and practical compaction method [J]. China power, 1995, 28(2):17-20 (in Chinese)

[4] Shao Tian-xiao. Mechanical calculation of wire in overhead power transmission line (second version) [M]. China Power Press, 2003: 112-129. (in Chinese) 